\title{
Reflexões sobre o tratamento da inclusão em duas coleções didáticas de língua estrangeira do PNLD
}

\author{
Vanessa Logue Dias \\ Universidade do Vale do Rio dos Sinos \\ Maria Edilene Kobolt \\ Universidade do Vale do Rio dos Sinos
}

\begin{abstract}
Resumo
A partir da teoria sociocultural de Vygotsky (1984) e de estudos a respeito da inclusão na escola, procuramos identificar em duas coleções didáticas de língua estrangeira (a saber, inglês e espanhol) do Programa Nacional do Livro Didático, se há atividades que conscientizam sobre as diferenças. Nos quatro livros da coleção de língua inglesa encontramos uma atividade que tratava das habilidades dos indivíduos com limitações físicas ou mentais e da inclusão destes nas práticas sociais. Já o material de espanhol não apresentou atividades sobre o tema. Entretanto, percebemos que há alguns momentos em que a inclusão poderia ser abordada. Considerando que as aulas de língua devem, também, formar cidadãos, concluímos que o tema da inclusão ainda precisa ser melhor explorado nos livros didáticos distribuídos nas escolas brasileiras.
\end{abstract}

Palavras-chave: inclusão, livros didáticos, língua estrangeira.

\begin{abstract}
In the research for this paper, based on Vygotsky's sociocultural theory (1984) and studies on the inclusion of students with disabilities in Brazilian schools, we aimed to identify in two textbook collections of English and Spanish as foreign languages whether there are tasks that raise students' awareness about differences. Using the four books of the English collection, we found one activity dealing with the skills of individuals with physical or mental limitations and the inclusion of these people in social practices. On the other hand, the Spanish material has no activities on the topic. However, it was observed that there were some texts and activities in which the inclusion of the disabled could have been addressed. Considering that language classes should also educate citizens, we conclude that the issue of inclusion of people with disabilities should be further explored in textbooks distributed in Brazilian schools.
\end{abstract}

Key-words: Inclusion of people with disabilities, textbooks, foreign languages

\section{INTRODUÇÃO}

Assim como explica Klein (2010), falar em escola inclusiva nos dias atuais pode soar redundante, visto que esta instituição tem e sempre teve a pretensão de incluir a todos. Porém, o termo vem sendo empregado para caracterizar práticas pedagógicas de inclusão de alunos 
com necessidades especiais ${ }^{1}$ nas escolas regulares. Neste sentido, entram em pauta nas discussões o que é inclusão ou exclusão, a preparação dos professores para trabalhar com diferentes tipos de alunos e necessidades educacionais, se o ambiente e a estrutura da escola estão preparados para receber todos os tipos de alunos, além do que diz respeito à interação entre os estudantes. Logo, essas discussões podem se estender ao material didático utilizado pelos alunos e escolhidos pelos professores, pois a preparação profissional do docente também é evidenciada na elaboração e utilização destas ferramentas.

Atualmente, professores da maioria das áreas de conhecimento da rede pública de ensino já contam com o apoio de livros didáticos para a elaboração de suas aulas. Por meio do Programa Nacional do Livro Didático (PNLD), várias coleções são desenvolvidas e submetidas à avaliação do PNLD para serem distribuídas para as escolas públicas de todo o Brasil. Das coleções selecionadas, o professor analisa e escolhe aquela que melhor responde às necessidades do contexto onde atua. Sendo assim, consideramos que essa escolha deve levar em conta questões como a visão de língua como prática social e a presença de atividades que vão além do caráter linguístico, englobando a formação do aluno como cidadão.

Por esta razão e, aproveitando os objetos de análise de nossas dissertações de mestrado, pretendemos analisar como a inclusão é trabalhada em duas coleções didáticas de língua estrangeira aprovadas no PNLD - uma de inglês e outra de espanhol. Considerando que as tarefas propostas nos livros devem trazer questões relevantes socialmente, a intenção está em observar se há textos e/ou tarefas que incluam a conscientização sobre as diferenças, sendo elas físicas ou intelectuais ${ }^{2}$.

\section{PRESSUPOSTOS TEÓRICOS}

Ao nos debruçarmos sobre a teoria sociocultural de Vygotsky (1984), é possível perceber que o desenvolvimento de qualquer indivíduo ocorre pela interação social, pois a diferença de níveis intelectuais é uma condição importante para a aprendizagem. Esse pesquisador explica que a aprendizagem ocorre a partir dos significados construídos dentro da interação social, sendo posteriormente internalizados pelo indivíduo, caracterizando um movimento que parte do plano externo (interpsicológico) para o interno (intrapsicológico).

\footnotetext{
${ }^{1}$ Optamos pelo uso da expressão "pessoas com necessidades especiais” por acreditarmos que estes indivíduos, apesar de possuírem limitações físicas ou intelectuais, não são, necessariamente, deficientes, pois, com os recursos necessários, são capazes de atuar nas mais diversas práticas sociais.

${ }^{2}$ Gostaríamos de agradecer à $\operatorname{Prof}^{\mathrm{a}} \operatorname{Dr}^{\mathrm{a}}$ Cátia de Azevedo Fronza pelas sugestões dadas durante a elaboração deste artigo.
} 
Para explicar este movimento, Vygotsky definiu etapas de aprendizagem que denominou de zonas de desenvolvimento, sendo elas: a Zona de Desenvolvimento Real, a Zona de Desenvolvimento Proximal (ZDP) e a Zona de Desenvolvimento Potencial. A primeira refere-se ao aprendizado já consolidado no sujeito, caracterizando aquilo que ele domina e é capaz de realizar sozinho. A última refere-se àquilo que o indivíduo ainda não sabe e, portanto, não pode realizar de forma autônoma. Já a segunda, a Zona de Desenvolvimento Proximal, refere-se à distância entre a primeira e última zona, pois explica o momento em que o indivíduo pode realizar tarefas além de sua capacidade, ou seja, além de sua Zona de Desenvolvimento Real, caso tenha apoio de um interlocutor mais capaz.

Vygotsky, em sua teoria, enfatizava o apoio de companheiros mais capazes, como professores ou adultos em interação com a criança ou aluno, para que o sujeito alcançasse um nível de competência superior ao seu. Entretanto, estudos neo-vygotskianos, como os de Donato (1994) e Lantolf (2000), postulam que, levando em conta o conhecimento que cada ser humano traz não é idêntico, a ZDP, atualmente, pode ser entendida como uma construção colaborativa de oportunidades para que os indivíduos aprendam de uma maneira efetiva, seja com professores ou com colegas de competência equivalente.

Considerando estes conceitos brevemente discutidos sobre a teoria sociocultural, ao pensarmos a escola inclusiva hoje tão debatida, a princípio, parece não haver sentido em manter crianças e alunos com necessidades especiais em escolas específicas para elas, reunindo aqueles com as mesmas limitações dentro de um espaço diferenciado. Manter estes indivíduos nesta situação os priva da interação com outros saberes e habilidades encontrados na escola regular que beneficiam não somente o estudante com limitações físicas ou intelectuais, mas também àqueles que já frequentam a instituição. Ademais, como citamos anteriormente, falar de escola inclusiva é redundante visto que essa instituição existe para atender a todos.

Olhando por outro ângulo, podemos pensar que as instituições que acolhem alunos especiais não são espaços de privação social e, consequentemente, de aprendizagem. Por vezes, na escola regular, o aluno com necessidades especiais sofre com o preconceito, com a falta de recursos e, assim, acaba por não interagir com o espaço no qual está inserido. Neste sentido, é preferível que o educando esteja em um ambiente em que interaja com pessoas em condições semelhantes, desenvolvendo o aprendizado, do que estar em um contexto em que, apesar da diversidade, não há interação.

Logo, como diz Klein (2010, p.11), “[...] os discursos sobre inclusão têm produzido desdobramentos no currículo, instituindo novas práticas que pretendem ser inclusivas, mas 
que também geram exclusões”. Sendo assim, as discussões que surgem relativas a esse tema concentram-se no que de fato é inclusão quando falamos da permanência de estudantes com necessidades especiais na escola regular. Apesar de esse ambiente propiciar a colaboração, impulsionando a aprendizagem de todos os envolvidos, muitas escolas não estão preparadas para receber esse tipo de aluno, tornando a inclusão um ato de exclusão. Logo, assim como exposto por Carvalho (2004), são excluídos tanto os que não conseguem ingressar nas escolas regulares, como aqueles que, estando matriculados, não aprendem de maneira efetiva por falta de estrutura e de formação dos professores.

Vale ressaltar que "[...] a educação dos alunos com necessidades educacionais tem os mesmos objetivos da educação de qualquer cidadão”. (FREITAS, 2006, p. 166). Portanto, independentemente de possuir ou não uma formação especializada e dos recursos que a escola oferece ao portador de necessidades especiais, é dever da escola e do professor cumprir com o compromisso de não ressaltar a diferença para não transformá-la em exclusão (FRONZA, 2012), sempre abrindo espaço para o trabalho colaborativo que envolva a aprendizagem de todos e, acima de tudo, deixar de lado o olhar sobre o que os alunos não conseguem fazer, direcionando o foco para aquilo que eles podem fazer de fato.

Nessa perspectiva, Fabris e Lopes (2000 apud Roos 2007) salientam que é preciso pensar o aluno especial não como aquele que possui um déficit de aprendizagem, mas como alguém que aprende de uma forma peculiar. É comum observarmos que esses estudantes são “[...] silenciados e narrados com palavras que não são suas”. (ROOS, 2007, p. 70). Por isso, as diversas nomenclaturas dadas a estes alunos, como a expressão "deficiente", podem prejudicar o trabalho docente, visto que já vêm carregadas de significados previamente estabelecidos e, portanto, repletas de preconceitos.

Assim como explica Freitas (2006, p. 170),

Talvez, influenciado pela experiência de seu próprio processo escolar, e pelas representações sociais das práticas escolares, quem inicia um curso de formação já traz consigo uma ideia preconcebida de aluno, sem se dar conta de que trabalhar com a diversidade é algo intrínseco à natureza da atuação docente e de que não faz sentido pensála como uma condição excepcional.

Por conseguinte, o docente, como profissional que forma cidadãos aptos a agir criticamente na sociedade na qual estão inseridos, deve despertar essa mesma conscientização em seus alunos. Assim como a escola e o professor precisam estar livres de preconceitos para atender os alunos especiais, os colegas desses estudantes também devem estar preparados para recebê-los de forma a incluí-los de maneira efetiva e significativa. Uma das formas de 
promover esse discurso em sala de aula é por meio do ensino dos conteúdos a serem ministrados pelo docente.

Tomando como exemplo nossa realidade como professoras de língua estrangeira (inglês e espanhol), de acordo com os Parâmetros Curriculares Nacionais (PCNs) (BRASIL, 1998) e com os Referenciais Curriculares do Rio Grande do Sul (RS, 2009), é preciso ir além do ensino da língua: deve-se formar cidadãos e ensinar a criticidade por meio do ensino dessa língua. Por conseguinte, pode-se despertar a reflexão a respeito das questões de inclusão através de textos na língua alvo que promovem discussões sobre necessidades especiais, normalidade, diferenças, etc.

De forma semelhante, considerando que as escolas públicas brasileiras já contam com o apoio de coleções didáticas consumíveis nas aulas de línguas estrangeiras, acreditamos ser essencial a presença dessas discussões nos livros didáticos a serem utilizados por nossos alunos, com atividades que promovam este tipo de reflexão. A inclusão de textos sobre o tema promove o exercício da cidadania, visto que atenta para uma nova forma de organização social, na qual aqueles que, por muito tempo, tiveram negado o acesso às práticas sociais, hoje estão presentes em nosso cotidiano, nas escolas e no mercado de trabalho.

É por essa razão que desenvolvemos esta breve investigação utilizando como objeto de análise alguns dos livros didáticos atualmente utilizados nas salas de aula de língua estrangeira nas escolas públicas do Brasil. Neste cenário, então, apresentamos nosso estudo.

\section{METODOLOGIA}

Os materiais a serem analisados são constituídos por duas coleções didáticas - uma de língua inglesa e outra de espanhol, ambas do Programa Nacional do Livro Didático. A escolha pelos livros em questão se deu devido ao fato de serem objeto de estudo das dissertações das autoras e pelo acesso que o público tem a elas: são parte de um programa federal, milhares de alunos as utiliza(m)(rão) e, por isso, as concepções trazidas pelas coleções didáticas, bem como as orientações a serem trabalhadas pelos professores, são de extrema importância. Neste sentido, pretendemos analisar se há textos e/ou tarefas que incluam a conscientização sobre as diferenças. 


\section{Descrição dos livros}

A fim de apresentar os objetos de análise e fornecer um panorama geral do que cada coleção traz, descreveremos as coleções didáticas a serem analisadas, começando pelo material de língua inglesa. A coleção intitulada It Fits, tendo como editor responsável Wilson Chequi, da editora SM (2014), é composta de quatro livros destinados aos anos finais do ensino fundamental, do sexto ao nono ano, a serem utilizados em escolas públicas de todo o Brasil.

Os quatro volumes possuem a mesma organização, sendo cada livro dividido em oito unidades. Cada unidade apresenta um tópico diferente, conta com duas seções de abertura para introduzir este tópico (Quick challenge e A first approach), e as seções que seguem são: Reading corner (para atividades de leitura); Words, words, words (para atividades de vocabulário e escrita); Grammar bits (explicações e exercícios de gramática); Pen to paper (atividades de escrita); Speaker's corner (focalizando a produção oral) e Open your ears (compreensão oral), nem sempre nesta ordem. Há, também, ao final do livro, elementos como Self assessment (para a auto-avaliação), Grammar reference (referências de gramática), Glossary (Glossário), Ideas for reading, Useful links (sugestões de materiais extras) e Bibliography (bibliografia). Todas as seções giram em torno de um tema, trabalhando as estruturas e vocabulário específicos do tópico nas quatro habilidades: compreensão escrita e oral e produção escrita e oral.

A coleção El arte de leer Español é composta por três livros ${ }^{3}$ destinados ao Ensino Médio/Politécnico para escolas públicas de todo Brasil e recomendado pelo MEC. Embora a lei $11.161^{4}$ refira-se à oferta do ensino da língua espanhola nas escolas públicas brasileiras, algumas instituições oferecem o idioma espanhol apenas no terceiro ano do EM e, em alguns casos, nos dois últimos anos do Ensino Médio/Politécnico. A organização do livro se dá por seções como: ¡Mira! (Olha), na qual são mostradas as características gerais da composição textual, geralmente seguidas de fotos e ilustrações (ainda que poucas); iAcércate! (te aproxima), uma seção voltada para atividades de reconhecimento e compreensão do conteúdo do texto que traz recursos expressivos usados pelo autor, características gerais da organização textual como vocabulário e conectores; ;Ojo! (Atenção) é uma seção na qual as atividades foram elaboradas para a sistematização de aspectos linguísticos como tempos verbais e

\footnotetext{
${ }^{3}$ Devido ao uso de apenas o volume 1 da coleção de espanhol nas escolas públicas, a análise será restrita ao primeiro volume.

${ }^{4}$ Em 05 de agosto de 2005, foi sancionada a lei 11.161, pelo então presidente Luiz Inácio Lula da Silva, exigindo que até 2010 todas as escolas públicas devessem ofertar o ensino de língua espanhola no Ensino Médio.
} 
gramática usada nos textos; ;Ahora tú! (Agora você), seção que estimula a prática dos conteúdos estudados, de forma sistematizada e geralmente com o auxílio da seção anterior ¡Ojo! ; ¡Dale! (Vamos lá), na qual geralmente há atividades em que os alunos fazem em grupos e é uma tentativa de contextualizar o que foi estudado nas aulas e podem ser atividades escritas ou orais. As duas últimas seções são Para consultar, que serve como um resumo de cada unidade, e Para curiosear (Curiosidades), cujo objetivo é despertar a curiosidade, acrescentando conhecimento além do livro, com sugestões de filmes, leituras etc. Além dessas seções descritas, existe, no final de cada livro desta coleção, a bibliografia. Não há glossário ou extensão de vocabulário ilustrativo e nem auto avaliação. Os temas de cada unidade são bem diversificados, porém pouco ilustrados.

\section{ANÁLISE DOS DADOS}

Ao direcionarmos o olhar para a coleção de língua inglesa It Fits, é possível perceber que, dos quatro livros da coleção, o material do $7^{\circ}$ ano apresentou uma atividade que discutia as habilidades de pessoas com necessidades especiais (Fig.1).

Percebe-se que a atividade conscientiza os alunos de que esses indivíduos não são deficientes, visto que desempenham atividades como qualquer pessoa, apesar de suas limitações físicas ou intelectuais. Ademais, o livro chama a atenção para o fato de que o convívio com pessoas com necessidades especiais é algo recente em nossa sociedade e, com base nisso, convida os estudantes a discutir o que é ser normal e como a inclusão pode ser positiva. Desta forma, o tópico gramatical que focaliza o uso do auxiliar $d o$ em suas formas negativa, interrogativa e na terceira pessoa, além do estudo de alguns verbos, é feito de maneira contextualizada, significativa, além de contribuir com a formação cidadã do aluno, visto que desenvolve seu senso crítico e chama a atenção a respeito de algo importante e atual na nossa sociedade: a inclusão.

Entretanto, esta é a única atividade da coleção que fala diretamente sobre o tema. Nos quatro livros, há diversas unidades que abordam temas como identidade, escola e relacionamentos, temas estes que poderiam ser aproveitados para iniciar discussões ou atividades envolvendo a inclusão e as diferenças na sociedade atual. 


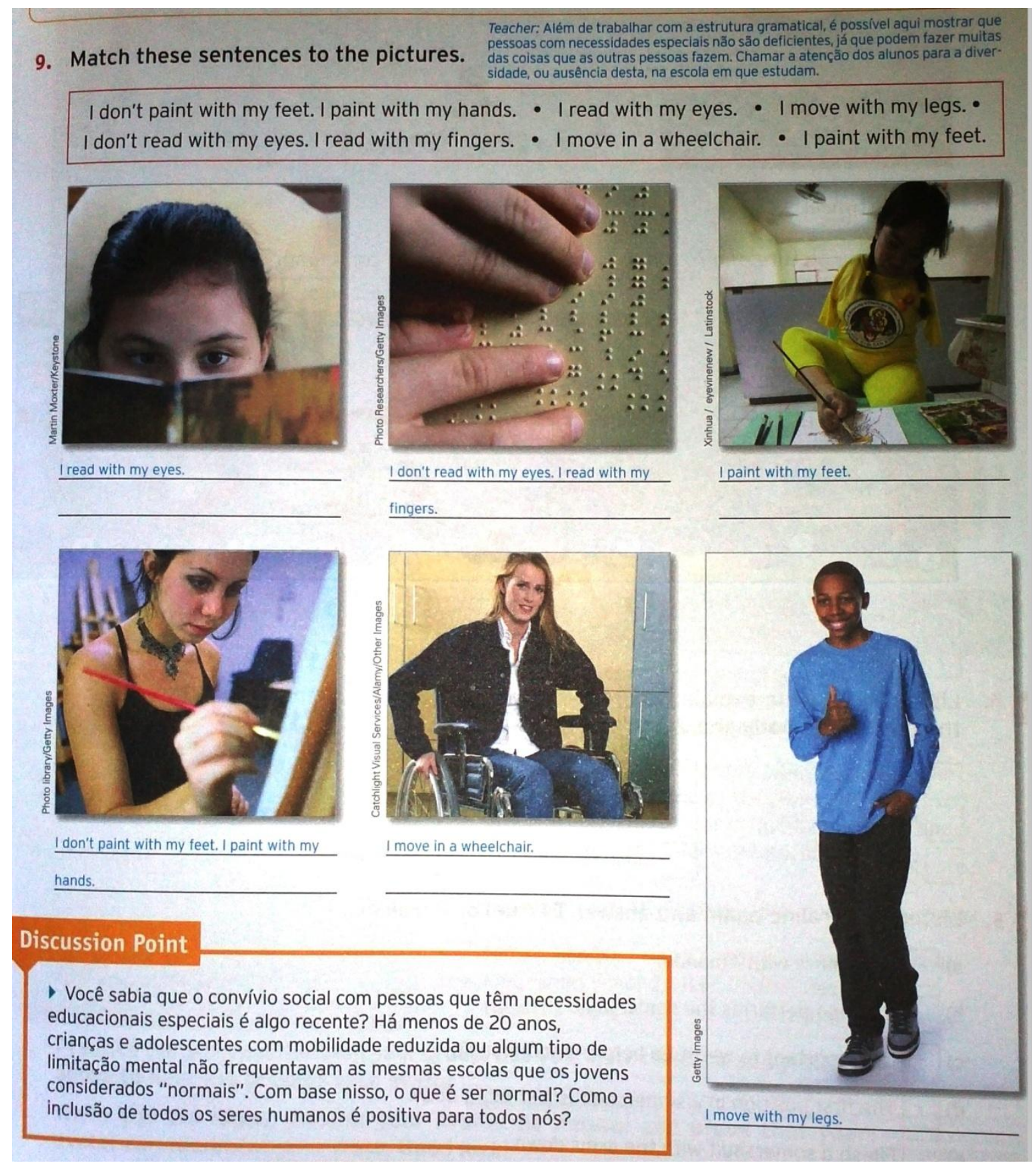

Livro It Fits, $7^{\circ}$ ano. (CHEQUI, 2012, p. 19).

Por outro lado, ao fazer a breve análise do livro El arte de leer en español, v.1, não foram constatadas atividades envolvendo o tema inclusão, mas acreditamos que há momentos em que o tema poderia ter sido abordado. Por exemplo, na unidade 1 são apresentados textos cujo tema central é a identidade. A nosso ver, este tema poderia ter sido aproveitado para trabalhar a construção das diferentes identidades sob a ótica da inclusão. De forma semelhante, a unidade 4 (El cuerpo y la calidad de vida) fala sobre o corpo, alimentação e esportes. Acreditamos que seria importante incluir aqui o exemplo de superação dos atletas 
paraolímpicos, expandindo, dessa forma, a visão de mundo e compreensão das diferentes possibilidades que a inclusão nos permite.

Já na Unidade 2 podemos considerar o texto ¿Qué es dislexia? (p.57) como uma tentativa de reflexão ao diferente. No entanto, há somente um trabalho voltado à compreensão de texto (Fig.2).

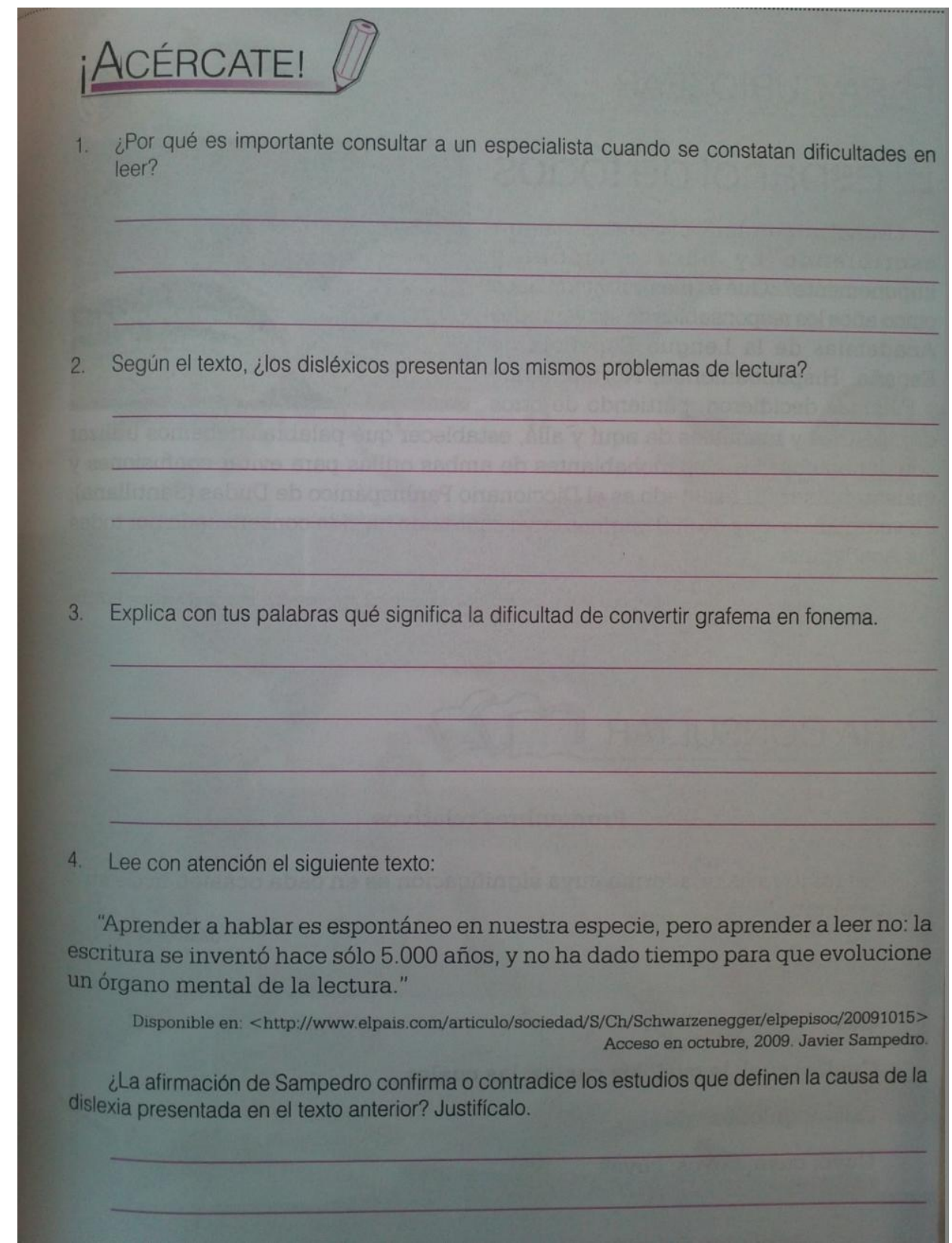

Fig. 2: Livro El arte de leer em Español, volume 1 (PICANÇO; VILLALBA, 2010, p. 59)

Entendemos que a discussão sobre as diferenças na sociedade poderia ser ampliada, pois o texto, além de falar sobre as características da dislexia, a explica como uma dificuldade e não como uma enfermidade biologicamente determinada. Assim, a diferença entre termos 
como habilidade, dificuldade, deficiência pode ser abordada, proporcionando ao aluno um momento de reflexão crítica sobre diferenças e, também, inclusão.

\section{CONSIDERAÇÕES FINAIS}

A partir dessa breve análise que levamos a cabo, podemos perceber que quase não há tarefas nas coleções didáticas que chamam atenção para o convívio das pessoas com necessidades especiais em nossa sociedade. Assim como salientamos anteriormente, documentos como os PCNs indicam que, muito mais do que ensinar a língua, as aulas de língua estrangeira devem ir além das questões linguísticas e precisam formar um cidadão capaz de agir no mundo de maneira crítica.

Devido às importantes discussões presentes na sociedade atual e à inclusão ocorrendo tanto nas escolas como no mercado de trabalho, é imprescindível que os materiais didáticos tragam questões relativas à inclusão nos textos e gêneros escritos ou orais a fim de despertar nos educandos a conscientização sobre termos como "normal" ou "deficiente", possibilitando que tenham uma visão sem preconceitos e não estereotipada de indivíduos com limitações físicas ou intelectuais e fazendo-os perceber que a interação entre diversos tipos de conhecimento e habilidades só tem a contribuir para qualquer pessoa.

Desta forma, sugerimos aos autores de coleções didáticas que elaborem mais tarefas relativas ao tema, fazendo com que, por meio da língua, seja inglês ou espanhol, o aluno possa ter conhecimento sobre a sociedade em que vive e sobre as diferentes formas de ver e agir no mundo. De forma semelhante e, considerando que, nem sempre, um livro didático atende a $100 \%$ das necessidades de determinado contexto, sugerimos aos professores de língua estrangeira que complementem, sempre que possível, seu material didático, levando em conta os aspectos discutidos aqui sobre inclusão com a intenção de formar cidadãos mais críticos e capazes de superar as barreiras do preconceito e de estereótipos.

\section{REFERÊNCIAS:}

BRASIL. Ministério da Educação. Secretaria da Educação Fundamental. (1998). Parâmetros curriculares nacionais - Linguagens, Códigos e suas Tecnologias. Brasília: MEC/SEEF. Disponível em: <http://portal.mec.gov.br>. Acesso em: 10 out. 2014.

CARVALHO, R. E. (2009). Educação inclusiva: alguns aspectos para reflexão. In. CARVALHO, R. E. Educação inclusiva com os pingos nos "is". 6. ed. Porto Alegre: Editora Mediação, pp. 65-75. 
CHEQUI, W. (2012). It Fits. São Paulo: Edições SM.

DONATO, R. (1994). Collective scaffolding in second language learning. In: LANTOLF, J. P.; APPEL, G. (Eds). Vygotskian approaches to second language research. Norwood, N.J.: Ablex Publishing Corporation, pp. 33-55.

FREITAS, S. N. (2006). Uma escola para todos: reflexões sobre a prática educativa. In: Inclusão: Revista da Educação Especial. Secretaria de Educação Especial/ MEC. Brasília, n. 3, Dez, pp. 37-40.

FRONZA, C. A. (2012). Sobre formação continuada e inclusão no ensino fundamental. In: GUIMARÃES, A. M. M.; KERSCH, D. F. (Org.). Caminhos da construção: projetos didáticos de gênero na sala de aula de língua portuguesa. 1. ed. Campinas: Mercado de Letras, pp. 79-89.

KLEIN, R. R. (2010). A escola inclusiva e alguns desdobramentos curriculares. In. KLEIN, R. R.; HATTGE, M. D. (Orgs.). Inclusão escolar: implicações para o currículo. São Paulo: Paulinas, pp. 11-27.

LANTOLF, J. P. (2000). Introducing sociocultural theory. In: LANTOLF, J. P. (Org.) Sociocultural theory and second language learning. Oxford: Oxford University Press, pp. 2750 .

PICANÇO, D.C.L.; VILLALBA, T. K. B. (2010). El arte de leer en español.V.1. Curitiba: Base editorial.

RIO GRANDE DO SUL. Secretaria de Estado da Educação. Departamento Pedagógico. (Org.). Referenciais Curriculares do Estado do Rio Grande do Sul: Linguagens, Códigos e suas Tecnologia. 1 ed. Porto Alegre: SE/DP, 2009.

ROOS, A. P. (2007). Olhares sobre as diferenças nas salas de atual. In.: LOPES, M. C.; DAL'IGNA, M. C.; ROOS, A. P. (Org.). In/exclusão: nas tramas da escola. 1. ed. Canoas: ULBRA, pp. 65-87.

VYGOTSKY, L. S. (1984). A formação social da mente: o desenvolvimento dos processos psicológicos superiores. Tradução de José Cipolla Neto, Luís Silveira Menna Barreto e Solange Castro Afeche. São Paulo: Martins Fontes.

\section{AS AUTORAS}

Vanessa Logue Dias possui graduação em Letras - Inglês pela Universidade do Vale do Rio dos Sinos - UNISINOS (2012). Atua como professora de língua inglesa e, atualmente, é aluna de Mestrado do Programa de Pós-Graduação em Linguística Aplicada da UNISINOS.

E-mail: vanessa.logdi@hotmail.com

Maria Edilene Kobolt possui graduação em Letras - Português/Espanhol pela Universidade do Vale do Rio dos Sinos - UNISINOS (2006). Atua como professora de língua espanhola e 
língua portuguesa e, atualmente, é aluna de Mestrado do Programa de Pós-Graduação em Linguística Aplicada da UNISINOS.

E-mail: edilenekobolt@ig.com.br 